\title{
Development and Validation of an LC-MS/MS Based Quantitative Assay for Marmoset Insulin
}

Robinson W. Goy', Hemanta K. Shrestha', Toni E. Ziegler', Natalie J. Dukes', Ricki J. Colman'², Amita Kapoor

-Wisconsin National Primate Research Center, 2Department of Cell and Regenerative Biology, University of Wisconsin, Madison WI

Keywords: insulin, marmosets, nonhuman primate model, metabolic syndrome, LC-MS/MS

Short title: Marmoset Insulin LC/MS/MS

\author{
Corresponding author and to whom reprints should be addressed: \\ Amita Kapoor, PhD \\ Wisconsin National Primate Research Center, \\ University of Wisconsin, \\ 1223 Capitol Court, Madison, WI 53715, USA. \\ Email: akapoor@wisc.edu
}

Grant support: National Institutes of Health Grants P51POD011106 (RWG, HKS, TEZ, NJD, RJC, AK), UW-Madison, UL1TR002373 to the Institute for Clinical and Translational Research at the UW-Madison (RWG, TEZ, AK), U34AG068466 (RJC, AK), and R01HD086057 (TEZ, NJD, RJC).

Disclosures: The authors have nothing to disclose. 


\section{ABSTRACT}

Introduction: Insulin is a peptide hormone that is secreted by the $\beta$ cells of the pancreas and is essential to the metabolism of carbohydrates, fats, and proteins in the body. The marmoset insulin peptide is not homologous with human insulin and therefore commonly available assays do not work for this species. Due to the increasing popularity of marmoset research, a simple, specific assay for the quantitation of marmoset insulin is needed. This study aimed to develop and validate a bottom-up proteomic workflow with trypsin digestion and analysis using LC coupled with triple quadrupole mass spectrometry (LC-MS/MS).

Methods: Marmoset serum proteins were subjected to denaturation, reduction, and enzymatic cleavage to extract a unique, 7 amino acid peptide for quantitation of marmoset insulin.

Resolution of the peptide was achieved by LC-MS/MS using electrospray ionization operating in positive mode. Calibration was achieved by aliquot dilution of fully synthetic marmoset insulin tryptic peptide into macaque serum. A stable-isotope labeled $\left({ }^{13} \mathrm{C},{ }^{15} \mathrm{~N}\right)$ synthetic marmoset insulin tryptic peptide was used as internal standard.

Results: The assay was fully validated according to bioanalytical method validation guidelines for linearity, precision, and dilution linearity using purified marmoset insulin. The limit of detection was $4.28 \mathrm{pmol} / \mathrm{L}$ and the limit of quantitation was $8.62 \mathrm{pmol} / \mathrm{L}$. Biological validation was achieved by comparison of samples previously run by radioimmunoassay and measurement of the marmoset insulin response to glucose via an oral glucose tolerance test (OGTT). The physiological range of marmoset insulin was shown to be 84.5 to $1222 \mathrm{pmol} / \mathrm{L}$.

Conclusions: This paper presents a simple, reproducible method to measure marmoset insulin using LC-MS/MS. 


\section{INTRODUCTION}

The common marmoset (Callithrix jacchus) has been used in biomedical research for decades [1]. Within the last 10 years, popularity of this model has increased dramatically, prompted to a large degree by awareness of their utility for aging, neuroscience, metabolic disorders, and transgenic and genomic editing research [2], [3]. Many factors make the marmoset an attractive model system including their genetic and physiological similarity to humans, relatively short lifespan, high fertility, rapid development, small size, and human-like social structure [4]. However, the lack of marmoset-specific biomarker assays has hampered the use of marmosets as models.

Metabolic syndrome is a cluster of biological factors characterized by abdominal obesity, dyslipidemia, hypertension, and type 2 diabetes mellitus (T2DM) that are associated with increased risk of multiple chronic diseases [5], [6]. Marmosets are a good model for metabolic syndrome as they exhibit metabolic dysfunction associated with high body weight and aging by six to eight years of age [7], [8]. Insulin, a peptide that is secreted by the pancreatic $\beta$ cells, is a biomarker for metabolic syndrome. Its main function is to maintain optimal blood glucose levels by facilitating glucose uptake by cells. Due to this role, high fasting insulin and an impaired insulin response to glucose levels are some of the hallmarks of metabolic dysfunction [9], [10].

The insulin peptide sequence is highly conserved across most species only differing in one to four positions with $92-98 \%$ identity [11]. While the marmoset pancreas exhibits the same structure, marker genes, and the presence of glucose transporters as human pancreas [12], the marmoset insulin peptide sequence differs in 5 amino acids from human and old world primates rendering limited or no immunologic cross-reactivity [13], [14].

Insulin is typically measured with immunological techniques, historically beginning with radioimmunoassay $(\mathrm{RIA})$ and now with immunochemiluminometric assays on automated platforms [15]. Ziegler et al. [16] fully validated an immunoassay to measure marmoset insulin 
using a polyclonal porcine insulin RIA where the antibody cross-reacted $100 \%$ with human insulin, but was less specific than the human insulin RIA (Millipore Corp., Billerica, MA). However, in 2016 , the antibody was depleted and the new one no longer cross-reacted with marmoset insulin. Our lab screened numerous commercially available immunoassays, including bead-based multiplex kits, to determine if an antibody used for insulin measurement in other species would cross-react with marmoset insulin, but this approach was unsuccessful. We considered creation of a custom immunoassay but it was logistically difficult. A relatively large amount (1-2 mg) of endogenous, pure analyte is required to create antibodies. Marmosets are in scarce supply due to their popularity as a research model, and being small monkeys with low blood volume, marmoset insulin is not commercially available, making the immunoassay approach not feasible.

We opted to develop a method to measure marmoset insulin using a bottom-up tryptic peptide LC-MS/MS approach. To our knowledge, there are currently no assays for any analytes in marmosets utilizing this technique. Since the marmoset insulin peptide sequence was published [13], we synthesized the tryptic peptide that was appropriate for quantitation [17]. Others have developed methods using LC-MS/MS for measurement of human insulin and other animal insulins. Their techniques include quantitation using B-chain [15], enrichment via immunocapture [18], and intact synthetic insulin analysis [19].

In this paper, we present the development and validation of a novel LC-MS/MS based method to quantify marmoset insulin utilizing a species-specific tryptic peptide. Utilization of this technology ensures independence from commercial sources. 


\section{MATERIALS AND METHODS}

Animal care. Marmosets used for validation in this study were housed at the Wisconsin National Primate Research Center (WNPRC) at the University of Wisconsin-Madison (UW-Madison). The study reported here was conducted with institutional animal care and use committee (IACUC) approval and in accordance with national standards on animal welfare.

Standards and reagents. HPLC grade water, ammonium hydroxide, and glacial acetic acid were purchased from Fisher Scientific (Waltham, MA); HPLC grade acetonitrile and methanol were purchased from Honeywell (Charlotte, NC); MS grade trypsin, iodoacetamide (IAA), high quality trifluoroacetic acid, and low protein binding microcentrifuge tubes were purchased from Thermo Fisher Scientific (Waltham, MA); Ammonium bicarbonate, dithiothreitol (DTT), and formic acid were purchased from Sigma-Aldrich (St. Louis, MO). Fully synthetic marmoset insulin tryptic peptide (MITP) was purchased from Genscript (>98\% purity) (Piscataway, NJ). Fully synthetic, isotopically labeled insulin tryptic peptide (MITP-IS) was purchased from Thermo Fisher Scientific (>95\% purity). All protein components were fully characterized by HPLC and MS by the manufacturers.

Preparation of calibrators, controls, and internal standards. A stock solution of MITP was prepared at $6 \mu \mathrm{mol} / \mathrm{L}$ in water and stored at $-80^{\circ} \mathrm{C}$ until use. Immediately before the assay, the stock solution was thawed and diluted to a working solution in $50 \mathrm{mM}$ ammonium bicarbonate buffer, $\mathrm{pH} 8.0$, to a final concentration of $3.45 \mathrm{nmol} / \mathrm{L}$. The working solution was aliquot diluted into macaque serum to generate an 8-point calibration series (i.e., 3100, 1550, 776, 388, 193.4, 96.8, 48.4, and $24.2 \mathrm{pmol} / \mathrm{L})$. Macaque serum was used as a blank matrix for this method since the insulin fragment is unique to marmosets and macaque serum does not contain native marmoset insulin. This serum came from quality control (QC) material that was used for other methods in the lab [e.g. 20]. QC pools for marmoset serum were collected and stored at $-80^{\circ} \mathrm{C}$ in $150 \mu \mathrm{l}$ aliquots. The isotopically labeled MITP used as internal standard (IS) was prepared in 
water at a concentration of $250 \mathrm{nmol} / \mathrm{L}$. Single use aliquots were stored at $-80^{\circ} \mathrm{C}$ and thawed before use. The IS was added to the calibrators, controls and serum samples after protein precipitation (See sample preparation below).

Preparation and purification of intact marmoset insulin. Briefly, marmoset insulin was purified from pancreas using a modification of published methods [14]. Pancreas was acquired from the WNPRC pathology unit when marmosets were at necropsy (for other studies or vet-directed). It was thawed, weighed, cut into small pieces, transferred to a tube containing 5 volumes of cold acidic alcohol $(0.2 \mathrm{M} \mathrm{HCl}$ in $75 \% \mathrm{EtOH})$ and ground with a Polytron grinder. After overnight incubation at $-20^{\circ} \mathrm{C}$, the mixture was centrifuged and the supernatant was collected. The supernatant was then precipitated, dissolved in $10 \mathrm{ml}$ of $1 \mathrm{M}$ acetic acid, dried, and then reconstituted with $100 \mu \mathrm{l}$ of acidified water and stored at $-80^{\circ} \mathrm{C}$ until purification. The marmoset insulin was purified by HPLC (Vanquish, Thermo Fisher) using reverse-phase C18(2) column (Luna 5 micron $250 \mathrm{~mm} \times 4.6 \mathrm{~mm}$, Phenomenex) and eluted with a linear gradient of $25-40 \%$ acetonitrile $(0.085 \%$ trifluoroacetic acid). The fraction containing the diode array detected $(214 \mathrm{~nm})$ insulin peak was dried in Speedvac, reconstituted with $100 \mu$ l of acidified $\mathrm{ddH} 2 \mathrm{O}$, and stored at $-80^{\circ} \mathrm{C}$. Confirmation that the fraction contained only the purified insulin peak was conducted with MALDI-TOF at the University of Wisconsin-Madison Biotechnology Center, Mass Spectrometry Facility.

Sample preparation. Serum from unknowns (used for biological validation, below) and QC pools were thawed, vortexed, and $50 \mu \mathrm{l}$ of serum was transferred to a low protein binding $1.5 \mathrm{ml}$ microcentrifuge tube. Large proteins were precipitated by a $1: 1$ addition of $1 / 49 / 50$ acetic acid/methanol/acetonitrile solution. Samples were adjusted to $\mathrm{pH}>9$ by addition of a $5 \%$ ammonium hydroxide solution and allowed to incubate at $-20^{\circ} \mathrm{C}$ for $30 \mathrm{~min}$. The resulting precipitate was centrifuged for $10 \mathrm{~min}$ at 13,000 rpm. Macaque serum was precipitated the same way. The supernatant was transferred to a clean low protein binding microcentrifuge tube and $10 \mu \mathrm{I}$ IS was added. Intact marmoset insulin and the MITP used for calibration was added to 
protein precipitated macaque serum at this step. To denature the native insulin, $50 \mu$ of $0.05 \%$ RapiGest SF surfactant (Waters Corporation) was added and allowed to incubate at $80^{\circ} \mathrm{C}$ for 10 min. Disulfide bonds were broken by adding DTT to a final concentration of $20 \mathrm{mM}$ and incubated at $60^{\circ} \mathrm{C}$ for $20 \mathrm{~min}$. The resulting free cysteines were alkylated by addition of IAA to a final concentration of $40 \mathrm{mM}$ followed by an incubation at room temperature, in the dark, for 30 min. The peptides were then enzymatically cleaved by addition of trypsin (Thermo scientific) and incubated at $37^{\circ} \mathrm{C}$ with mild agitation overnight. The trypsin reaction was stopped by raising the $\mathrm{pH}$ to $>4$ and incubated at $37^{\circ} \mathrm{C}$ for $30 \mathrm{~min}$.

Sample cleanup was tested using Oasis MCX 1cc solid phase extraction (SPE) cartridges and Oasis MCX 96-well pelution SPE plate (Waters corporation). For the 1cc MCX SPE cartridges, MITP was eluted in 2 column volumes of $5 \%$ ammonium hydroxide in methanol. The resulting eluate was dried via vacuum centrifugation and reconstituted in $30 \mu \mathrm{l} 20 \%$ acetonitrile in water with $0.1 \%$ formic acid. For the MCX $\mu$ elution plate, MITP was eluted twice with $25 \mu \mathrm{l}$ 5\% ammonium hydroxide in methanol, and the resulting eluate was diluted 1:1 with HPLC grade water for analysis.

Analytical chromatography and MS conditions. Samples were analyzed on a QTRAP 5500 triple-quadrupole linear ion trap mass spectrometer (Sciex) equipped with an electrospray ionization (ESI) source. The system included two Shimadzu LC20ADXR pumps and a Shimadzu SIL20ACXR autosampler. A sample of $20 \mu$ was injected onto a XSelect CSH C18 XP column (2.1 mm x $100 \mathrm{~mm}, 2.5 \mu \mathrm{m}, 130 \AA \AA$ ) (Waters) analytical separation was achieved using a mobile phase consisting of water with $0.1 \%$ formic acid (Solution $\mathrm{A}$ ) and acetonitrile with $0.1 \%$ formic acid (Solution B), at a flow rate of $200 \mu \mathrm{l} / \mathrm{min}$. MITP was eluted by a linear gradient of $15 \%$ to $25 \%$ solution B over 5 min. Solution B was increased to $100 \%$ over the next $0.1 \mathrm{~min}$ and held for $0.5 \mathrm{~min}$, followed by a decrease back to starting conditions of $15 \%$ solution B over $0.1 \mathrm{~min}$ and held for $3 \mathrm{~min}$ for a total run time of 8 minutes.

\section{Method Validation}


The developed method was validated for the calibration curve performance and precision in determination of insulin in marmoset serum according to bioanalytical method validation guidelines of the US Food and Drug Administration [21].

Linearity, limit of detection (LOD), and limit of quantitation (LOQ). A calibration curve was developed by multiplying the ratio of the peak area of the calibrator to the peak area of IS and the concentration of the calibrator in pmol/L. Linearity was evaluated by monitoring coefficient of determination $\left(\mathrm{r}^{2}\right)$ of the calibration curves. The performance of the assay was characterized by determining the LOD and the LOQ. QC pools were serially diluted and measured 5 times to calculate the concentration at which the CV was no higher than $20 \%$ and the LOD was calculated from the marmoset pool dilution which could be measured at a CV $>20 \%$. The LOD and LOQ were also measured in 5 replicates in calibrators spiked in macaque serum. Precision. Precision was evaluated by measuring the coefficient of variation (CV) of the measurements of the high and low QC pool. QC data was collected at two levels (whole marmoset serum "high QC" and 1:1 diluted marmoset serum "low QC"). Values for the QC pools were collected in 20-25 determinations over the course of 2 months in separate batches.

Dilutional linearity. A portion of the purified insulin was diluted to demonstrate dilutional linearity and to confirm that the method developed was measuring intact marmoset insulin.

\section{Biological Validation}

Oral glucose tolerance testing (OGTT). OGTT was conducted in 6 adult marmosets to demonstrate their insulin response to dextrose. These marmosets were part of a larger study to understand the role of dietary fat on brain development so a wide physiological range of glucose and insulin were expected. Subjects consisted of two females and four males between the ages of nineteen and twenty-five months. The details of housing and husbandry are published [22]. Dextrose volume was based on marmoset weight ( $50 \%$ dextrose solution at $5 \mathrm{~mL} / \mathrm{kg})$. A $0.5 \mathrm{ml}$ baseline blood sample was collected to measure starting glucose and insulin concentration after 
which, monkeys were administered the calculated volume of dextrose orally. Blood draws were then taken at $15,30,60$, and 120 minutes. Glucose was measured with a glucometer (YSI 2900D). Blood samples were processed for serum and stored at $-80^{\circ} \mathrm{C}$.

Method comparison. Twenty-four marmoset serum samples (stored at $-20^{\circ} \mathrm{C}$ ) that had previously been run for measurement of insulin and had sufficient volume $(50 \mu \mathrm{L})$ remaining were tested with the newly developed method. These were the last samples that Assay Services ran before the manufacturer changed the antibody of the validated porcine insulin RIA and they were stored with the intention of being used to validate a new marmoset insulin assay.

Data analysis. Analyst software version 1.6.2 was used for all LC-MS/MS data acquisition and analysis. All statistical analyses were performed using Analyst and Prism version 8.4.3. For the OGTT, glucose and insulin levels were analyzed by one-way repeated measures analysis of variance (ANOVA) (time) with Tukey's multiple comparison test and was qualitatively analyzed by determining the percent change from baseline for glucose and insulin. The comparison between samples run by RIA and the new LC-MS/MS method were analyzed using Pearson's correlation analysis. The calibration curve and the intact marmoset dilution series were analyzed with linear regression. 


\section{RESULTS}

Optimization of sample preparation. Trypsin concentration was optimized by addition of 0.1 , $0.2,0.3,0.4$ and $0.5 \mu \mathrm{g}$ in triplicate. Area counts of marmoset insulin plateaued with $0.3 \mu \mathrm{g}$, therefore that concentration was chosen for all further experiments. The digestion time was 16 hours based on manufacturer recommendations and consideration of lab logistics.

Strong cation exchange mixed-mode (MCX) SPE was chosen for sample cleanup and desalting and tested in cartridge and $\mu$ elution plates form. The cartridge required sample dry-down before reconstitution and injection which led to protein adsorption and inconsistent results. Protein precipitation also occurred resulting in poor chromatography and increasing backpressure. For these reasons, the 96-well pelution MCX SPE plate (Waters corporation) was chosen for sample clean up as the dry-down step was not required.

\section{Optimization of the tryptic peptide, mass spectrometry, and chromatography conditions.}

The marmoset insulin tryptic peptide (GFFYAPK) was selected for quantitation based on uniqueness, ease of synthesis, and multiple reaction monitoring (MRM) compatibility. The unique amino acid sequence for the marmoset insulin tryptic peptide was confirmed by running a basic local alignment search tool (BLAST) search and did not share similarities with any common interferences. The intact marmoset insulin peptide differed from human insulin at 5 amino acids and the MITP differed from the same tryptic fragment for human insulin by 1 amino acid (GFFYTPK in human). The MITP was simple to synthesize and, due to its moderate hydrophobicity, made it highly compatible with MRM detection (Supplementary Figure 1). Heavy labeled marmoset insulin tryptic peptide (GFFYAPK $\left({ }^{13} \mathrm{C},{ }^{15} \mathrm{~N}\right)$ ) was used as an IS. For each peptide and IS, collision-induced dissociation products of multiple charged precursors were detected by MRM mass spectrometry operating in positive ion mode using ESI. The electrospray voltage, source temperature, and ion source gases 1 and 2 were $5500 \mathrm{~V}, 650^{\circ} \mathrm{C}, 35$ units, and 60 units, respectively. For MS/MS optimization, $1 \mu \mathrm{g} / \mathrm{ml}$ solutions of MITP and MITP-IS were made in 20:80 acetonitrile:water and were directly infused at a flow rate of 
$10 \mu \mathrm{l} / \mathrm{min}$. The most intense isotopic peak of the $\mathrm{MH}_{2}{ }^{+2}$ ion of the marmoset insulin tryptic peptide and heavy labeled peptide was used as the parent peak. This also corresponded to the data provided by the manufacturer of the fragment (Genscript, Thermo). The most intense product ions that gave a higher $\mathrm{m} / \mathrm{z}$ than that of the parent ion were chosen for quantifier and qualifier peaks. MRM transitions and charge states for each peptide fragment and IS are summarized in Table 1. Representative chromatograms for the marmoset insulin tryptic peptide, the internal standard, and blank are shown in Figure 1 and representative spectra of the MITP are presented in Supplementary Figure 2.

Chromatographic conditions were initially chosen based on the hydropathy of the target peptide; since it was hydrophobic, a low starting concentration of solution B 10 to $30 \%$ B was chosen. As expected, the peptide eluted from the column within the linear gradient, however at $50^{\circ} \mathrm{C}$, the peptide eluted earlier than intended at $1.7 \mathrm{~min}$ and peak splitting was observed. The column oven was reduced to $35^{\circ} \mathrm{C}$ and the peak eluted later in the gradient $(3.27 \mathrm{~min})$ with no splitting.

\section{Assay Validation}

Linearity, limit of detection ( $L O D)$, and limit of quantitation (LOQ). The ratio of the peak area of the analyte to the IS was used to calculate the concentrations for the calibration curve. A weighted linear model $(1 / x)$ with linear regression was used. The calibration curve had a range of $3100 \mathrm{pmol} / \mathrm{L}$ to $24.2 \mathrm{pmol} / \mathrm{L}$ over eight points. The calibration range was based on the concentration of human insulin measured by LC-MS/MS [15], but started at a higher concentration based on preliminary data from a marmoset insulin pool. Accuracy of calibration was within $5 \%$ at each point measured over 5 runs, including the lowest calibrator. Calibration data is presented in Figure 2. Biological validation data presented below showed that the range of calibration required for the physiological range of marmoset insulin was well above the LOQ. QC pools containing intact marmoset insulin and MITP spiked into macaque serum were used to calculate the LOD and LOQ. The LOD for the method was determined by assaying diluted 
marmoset serum in 5 replicates to measure an LOD of $4.28 \pm 1.05 \mathrm{pmol} / \mathrm{L}$ which had a CV of 24.48\%. This was confirmed by spiking MITP at a concentration of $6.05 \mathrm{pmol} / \mathrm{L}$ and assaying 5 times. The accuracy was $87 \% \pm 29.8 \%$. Similarly, the LOQ was calculated based on measurement of the diluted QC pool 5 times and was $8.62 \pm 1.15 \mathrm{pmol} / \mathrm{L}$ with a CV of $13.29 \%$. The accuracy of $12.1 \mathrm{pmol} / \mathrm{L}$ of MITP spiked into macaque serum was $110 \% \pm 22 \%$. Precision. Precision was evaluated by measuring the $\mathrm{CV}$ of the measurements of the high and low QC pool (Table 2). The intra- and inter-assay CVs for both QC pools were within acceptable range.

Dilutional linearity. A reference preparation of intact marmoset insulin was not available. In order to definitively prove that the method was measuring marmoset insulin, it was purified directly from marmoset pancreas and used in dilutional linearity experiments in macaque serum. The lyophilized material was diluted 0-10,000 times. The back-calculated values were determined based on the calibration curve and the $r^{2}$ value was 0.9999 (Table 3). The 0 (neat) and 1:100 dilutions were beyond the range of the calibration curve and the concentrations were extrapolated.

\section{Biological validation}

Oral glucose tolerance testing. The basal levels of glucose and insulin were $111-144 \mathrm{mg} / \mathrm{dL}$ and 128-628pmol/L, respectively. One-way (time) repeated measures ANOVA was significant $(p=0.0003)$ and demonstrated that glucose levels rose significantly above baseline by 15 mins and stayed high until 60 mins. By 120 mins, the glucose levels were indistinguishable from baseline. Overall, insulin concentrations demonstrated an effect of time $(p=0.0037)$ and post hoc analysis demonstrated there was a trend towards insulin being higher than baseline at 15 mins $(p=0.0832)$ and 30 mins $(p=0.06)$. The percent change in glucose and insulin from baseline are shown in Figure 3. This data also provided the physiological range of marmoset 
insulin since this was the first time that marmoset insulin was measured directly. This range was 103.8 to $1222 \mathrm{pmol} / \mathrm{L}$.

Comparison with commercial RIA. There was a strong correlation between the previously validated porcine RIA for marmoset insulin and the current method (Figure 4, $r=0.82, p<$ 0.0001). Based on the LC-MS/MS data, the physiological range was 84.5 to $1164 \mathrm{pmol} / \mathrm{L}$, similar to the results of the OGTT experiment. 


\section{DISCUSSION}

This paper presents a novel LC-MS/MS based method utilizing a synthetic species-specific tryptic peptide to measure insulin in marmoset serum. The validations demonstrated that the method is reproducible, precise, and accurate according to the guidelines of FDA [21]. Biological validation with OGTT confirmed the expected changes in insulin and glucose levels reported earlier [16] and the concentration changes of glucose and insulin were comparable to humans [23]. The OGTT provided evidence that the method can reliably measure changes in insulin level during physio-pathological conditions. For the second part of the biological validation, high correlation between values obtained for samples previously run using the validated porcine RIA [16] and the current method provided further reliability of the method. To our knowledge, this is now currently the only method to measure marmoset insulin available.

We opted to measure a tryptic peptide of marmoset insulin rather than the intact B chain of the peptide as was done in human studies [15], [19] for two reasons. First, the B chain was harder to synthesize and more expensive than a tryptic peptide. It would have also been difficult to purchase a heavy labeled version of the marmoset B chain for IS. Human studies circumvent this issue by using bovine B chain as the IS, but due to the uniqueness of the structure of the marmoset B chain and that external calibrators and QC material was not readily available, we deemed it critical to have a heavy labeled version of the exact peptide that was being measured for this study. Second, in order to fully develop a marmoset model of aging and disease, there are other important biomarkers that require assay development. The use of trypsin to digest the peptides creates predictable tryptic fragments [17] making this technology adaptable for other metabolites. Furthermore, the simple sample preparation using the $\mu$-elution mixed-mode cation exchange solid-phase extraction plate is amenable to inclusion of additional analytes, which is important due to the low blood volume of marmosets. 
There are a number of studies that have been conducted that have measured marmoset insulin and they have exclusively used the discontinued RIA from Millipore that was validated for marmosets [16]. In the Ziegler study, OGTT and stimulation of marmoset pancreas in vitro demonstrated the biological validity of the assay. Parallelism and accuracy were also demonstrated. The range of the insulin response for the OGTT and the pancreatic stimulation experiments was approximately 2.5 to $80 \mu \mathrm{IU} / \mathrm{mL}$. In a study conducted to understand the impact of early life obesity on metabolic parameters, at 12 months of age, obese animals (16.45 $+3.04 \mu \mathrm{lU} / \mathrm{mL})$ had significantly higher insulin levels than the control animals $(1.01+0.25 \mu \mathrm{lU} /$ $\mathrm{mL}$ ) [7]. Another study conducted to look at the fasting insulin concentration in female marmosets to understand the combined and independent effects of aging and obesity on metabolism in marmosets showed that the range of insulin was from approximately 2 to 110 $3.04 \mu \mathrm{IU} / \mathrm{mL}$ [8]. Before the porcine RIA was validated for marmoset insulin, Wachtman et al., conducted a study to measure the effect of diet on the development of obesity and T2DM in marmosets. They showed that both a high sugar or high fat diet resulted in profound pancreatic islet hyperplasia, which suggested a compensation for increased insulin requirements, though insulin was not measured [24].

Conventional insulin concentration units $(\mu \mathrm{lU} / \mathrm{mL})$ are based on bioefficiency which is defined as the amount of insulin required to achieve a standard glycemic effect. This number has changed several times based on differences in standards and purity of insulin preparations [25]. The factor to convert to SI units is based on the molecular weight of insulin, which differs among different species. For example, human insulin is $5808 \mathrm{Da}$, marmoset insulin is $5764 \mathrm{Da}$, and porcine insulin is $5777 \mathrm{Da}$ [26]. The porcine RIA kit insert [16] did not provide any information about the conversion factor that could be used to convert to SI units so we chose the factor $6(1 \mu \mathrm{lU} / \mathrm{mL}=6 \mathrm{pmol} / \mathrm{L})$ [25]. With this conversion factor, the range of marmoset insulin measured by RIA (approximately 6 to $600 \mathrm{pmol} / \mathrm{L}$ ) is lower than the range that we present in this paper (84.5 to $1222 \mathrm{pmol} / \mathrm{L})$. 
While the RIA was validated, the cross-reactivity of the porcine antibody with marmoset insulin was not investigated. Comparison of the range of marmoset insulin observed in this study with human insulin are similar. In two studies, human insulin measured by LC-MS/MS was shown to be from 18-1080 pmol/L [15] and 86.08 - $774.8 \mathrm{pmol} / \mathrm{L}$ [27]. Based on these data, the RIA could have been underestimating marmoset insulin in serum, especially at high concentrations, but it is not possible to know with certainty as marmoset insulin standard material is not available.

There are two limitations to the method validation. First, it is not possible to do a recovery study in the traditional manner since we did not have precise amounts of intact marmoset insulin. We partially overcame this by spiking relative amounts of purified marmoset insulin at different dilutions and demonstrating the linearity and back-calculated values. This obstacle is part of the second limitation which is that we cannot be certain of the absolute concentrations of marmoset insulin since there is no verified standard material to trace back to. Nonetheless, based on the validation parameters presented, we are confident that we have a specific, reproducible method for measurement of marmoset insulin.

In summary, we have developed the only quantitative LC-MS/MS based assay specific for marmoset insulin. It is not reliant on commercially available antibodies or immunoassays and is easily transferable to other labs that have the capacity to measure peptides by LC-MS/MS. 
bioRxiv preprint doi: https://doi.org/10.1101/2021.06.24.449777; this version posted June 24, 2021. The copyright holder for this preprint (which was not certified by peer review) is the author/funder. All rights reserved. No reuse allowed without permission.

\section{ACKNOWLEDGMENTS}

Special thanks to the staff at Assay Services and the Scientific Protocol Implementation at the

WNPRC and the Mass Spectrometry Facility at the UW-Madison Biotechnology Center. 


\section{REFERENCES}

[1] K. Mansfield, "Marmoset models commonly used in biomedical research," Comp Med, vol. 53, no. 4, pp. 383-392, Aug. 2003.

[2] J. Kropp, A. Di Marzo, and T. Golos, "Assisted reproductive technologies in the common marmoset: an integral species for developing nonhuman primate models of human diseases," Biol Reprod, vol. 96, no. 2, pp. 277-287, Feb. 2017, doi: 10.1095/biolreprod.116.146514.

[3] W. Yuan, S. Fukuda, T. Inoue, H. Okochi, E. Sasaki, and M. Shimoda, "Establishment of a diabetes mellitus type 1 model in the common marmoset," Sci Rep, vol. 9, Oct. 2019, doi: 10.1038/s41598-019-51199-5.

[4] K. E. Fischer and S. N. Austad, "The development of small primate models for aging research," ILAR J, vol. 52, no. 1, pp. 78-88, 2011, doi: 10.1093/ilar.52.1.78.

[5] Expert Panel on Detection, Evaluation, and Treatment of High Blood Cholesterol in Adults, "Executive Summary of The Third Report of The National Cholesterol Education Program (NCEP) Expert Panel on Detection, Evaluation, And Treatment of High Blood Cholesterol In Adults (Adult Treatment Panel III)," JAMA, vol. 285, no. 19, pp. 2486-2497, May 2001, doi: 10.1001/jama.285.19.2486.

[6] J. X. Moore, "Metabolic Syndrome Prevalence by Race/Ethnicity and Sex in the United States, National Health and Nutrition Examination Survey, 1988-2012," Prev. Chronic Dis., vol. 14, 2017, doi: 10.5888/pcd14.160287.

[7] M. L. Power, C. N. Ross, J. Schulkin, T. E. Ziegler, and S. D. Tardif, "Metabolic consequences of the early onset of obesity in common marmoset monkeys," Obesity (Silver Spring), vol. 21, no. 12, pp. E592-598, Dec. 2013, doi: 10.1002/oby.20462.

[8] S. D. Tardif, K. G. Mansfield, R. Ratnam, C. N. Ross, and T. E. Ziegler, "The marmoset as a model of aging and age-related diseases," ILAR J, vol. 52, no. 1, pp. 54-65, 2011, doi: 10.1093/ilar.52.1.54.

[9] K. G. M. Alberti, P. Zimmet, and J. Shaw, "The metabolic syndrome-a new worldwide definition," The Lancet, vol. 366, no. 9491, pp. 1059-1062, Sep. 2005, doi: 10.1016/S0140-6736(05)67402-8.

[10] M. Laakso, "How Good a Marker Is Insulin Level for Insulin Resistance?," American Journal of Epidemiology, vol. 137, no. 9, pp. 959-965, May 1993, doi:

10.1093/oxfordjournals.aje.a116768.

[11] J. P. Mayer, F. Zhang, and R. D. DiMarchi, "Insulin structure and function," Peptide Science, vol. 88, no. 5, pp. 687-713, 2007, doi: https://doi.org/10.1002/bip.20734.

[12] R. R. Plentz et al., "Islet microarchitecture and glucose transporter expression of the pancreas of the marmoset monkey display similarities to the human," Islets, vol. 4, no. 2, pp. 123-129, Apr. 2012, doi: 10.4161/isl.19254.

[13] M. Wallis, "New insulin-like growth factor (IGF)-precursor sequences from mammalian genomes: the molecular evolution of IGFs and associated peptides in primates," Growth Hormone \& IGF Research, vol. 19, no. 1, pp. 12-23, Feb. 2009, doi:

10.1016/j.ghir.2008.05.001.

[14] J. H. Yu, J. Eng, and R. S. Yalow, "Isolation and amino acid sequences of squirrel monkey (Saimiri sciurea) insulin and glucagon," Proc Natl Acad Sci U S A, vol. 87, no. 24, pp. 9766-9768, Dec. 1990, doi: 10.1073/pnas.87.24.9766.

[15] Z. Chen, M. P. Caulfield, M. J. McPhaul, R. E. Reitz, S. W. Taylor, and N. J. Clarke, "Quantitative Insulin Analysis Using Liquid Chromatography-Tandem Mass Spectrometry in 
a High-Throughput Clinical Laboratory," Clinical Chemistry, vol. 59, no. 9, pp. 1349-1356, Sep. 2013, doi: 10.1373/clinchem.2012.199794.

[16] T. E. Ziegler et al., "Development of metabolic function biomarkers in the common marmoset, Callithrix jacchus," Am. J. Primatol., vol. 75, no. 5, pp. 500-508, May 2013, doi: 10.1002/ajp.22126.

[17] A. N. Hoofnagle et al., "Recommendations for the Generation, Quantification, Storage, and Handling of Peptides Used for Mass Spectrometry-Based Assays," Clinical Chemistry, Jan. 2015, doi: 10.1373/clinchem.2015.250563.

[18] Y.-X. L. Yan Ke, “Quantitation of Insulin Analogue Glargine and Its Two Metabolites M1 and M2 on Triple Quad 6500 and Triple TOF 5600 LC-MS/MS Systems in a Dog Toxicokinetics Study," Journal of Analytical \& Bioanalytical Techniques, vol. s5, no. 01, 2014, doi: 10.4172/2155-9872.S5-004.

[19] E. E. Chambers, C. Legido-Quigley, N. Smith, and K. J. Fountain, "Development of a fast method for direct analysis of intact synthetic insulins in human plasma: the large peptide challenge," Bioanalysis, vol. 5, no. 1, pp. 65-81, Jan. 2013, doi: 10.4155/bio.12.290.

[20] B. P. Kenealy et al., "Neuroestradiol in the hypothalamus contributes to the regulation of gonadotropin releasing hormone release," J. Neurosci., vol. 33, no. 49, pp. 19051-19059, Dec. 2013, doi: 10.1523/JNEUROSCI.3878-13.2013.

[21] Food and Drug Administration, "Bioanalytical Method Validation Guidance for Industry," p. 44, 2018.

[22] H. Ash, T. E. Ziegler, and R. J. Colman, "Early learning in the common marmoset (Callithrix jacchus): Behavior in the family group is related to preadolescent cognitive performance," Am J Primatol, vol. 82, no. 8, p. e23159, Aug. 2020, doi: 10.1002/ajp.23159.

[23] T. P. J. Solomon and A. K. Blannin, "Changes in glucose tolerance and insulin sensitivity following 2 weeks of daily cinnamon ingestion in healthy humans," Eur J Appl Physiol, vol. 105, no. 6, p. 969, Jan. 2009, doi: 10.1007/s00421-009-0986-9.

[24] L. M. Wachtman, J. A. Kramer, A. D. Miller, A. M. Hachey, E. H. Curran, and K. G. Mansfield, "Differential contribution of dietary fat and monosaccharide to metabolic syndrome in the common marmoset (Callithrix jacchus)," Obesity (Silver Spring), vol. 19, no. 6, pp. 1145-1156, Jun. 2011, doi: 10.1038/oby.2010.303.

[25] J. L. Knopp, L. Holder-Pearson, and J. G. Chase, "Insulin Units and Conversion Factors: A Story of Truth, Boots, and Faster Half-Truths," J Diabetes Sci Technol, vol. 13, no. 3, pp. 597-600, Oct. 2018, doi: 10.1177/1932296818805074.

[26] G. E. Sonnenberg, F. W. Kemmer, H. J. Cüppers, and M. Berger, "Subcutaneous use of regular human insulin (Novo): pharmacokinetics and continuous insulin infusion therapy," Diabetes Care, vol. 6 Suppl 1, pp. 35-39, Apr. 1983.

[27] A. Thomas, R. Yang, S. Petring, L. Bally, and M. Thevis, "Simplified quantification of insulin, its synthetic analogs and C-peptide in human plasma by means of LC-HRMS," Drug Testing and Analysis, vol. 12, no. 3, pp. 382-390, 2020, doi: https://doi.org/10.1002/dta.2765. 


\section{TABLES}

Table 1. Optimized MS/MS parameters for marmoset insulin tryptic peptide (MITP) and the internal standard (IS).

\begin{tabular}{lllllll}
$\begin{array}{l}\text { Compound } \\
\text { Name }\end{array}$ & $\begin{array}{l}\text { Parent } \\
(\mathbf{m} / \mathbf{z})\end{array}$ & $\begin{array}{l}\text { Daughter } \\
(\mathbf{m} / \mathbf{z})\end{array}$ & $\begin{array}{l}\text { Dwell time } \\
(\mathbf{m s})\end{array}$ & $\begin{array}{l}\text { DP } \\
(\mathbf{v})\end{array}$ & $\begin{array}{l}\text { CE } \\
(\mathbf{v})\end{array}$ & Ion Type \\
\hline Quantitative & 415.4 & 625.3 & 195 & 82 & 16 & $\begin{array}{l}\mathrm{y}_{5} \text { Tryptic } \\
\text { Peptide }\end{array}$ \\
Qualifier & 415.4 & 478.3 & 195 & 82 & 17 & $\begin{array}{l}\mathrm{y}_{4} \text { Tryptic } \\
\text { Peptide }\end{array}$ \\
IS & 419.4 & 633.4 & 195 & 82 & 15.65 & $\mathrm{y}_{5}$
\end{tabular}

Table 2. Marmoset insulin quality control (QC) pool data.

\begin{tabular}{llll} 
QC pool & $\begin{array}{l}\text { Calculated } \\
\text { concentration of } \\
\text { marmoset insulin } \\
\text { (pmol/L } \pm \text { SD) }\end{array}$ & $\begin{array}{l}\text { Intra-assay CV (\# } \\
\text { batches) }\end{array}$ & $\begin{array}{l}\text { Inter-assay CV (n } \\
\text { replicates) }\end{array}$ \\
\hline Low & $626 \pm 59.8$ & $2.04 \%-10.2 \%(3)$ & $9.55 \%(22)$ \\
High & $1304.16 \pm 92.5$ & $2.66 \%-5.78 \%(3)$ & $7.09 \%(23)$
\end{tabular}

Table 3. Purified intact marmoset insulin spiked into macaque serum and diluted to generate a linear regression $\left(r^{2}=0.9999\right)$.

\begin{tabular}{lll} 
Dilution & Peak area counts & $\begin{array}{l}\text { Back calculated } \\
\text { concentration } \\
\text { (pmol/L } \pm \text { SD) }\end{array}$ \\
\hline Neat & $2.34 \mathrm{E}+07$ & $539,333 \pm 26,102$ \\
$1: 100$ & $2.76 \mathrm{E}+05$ & $5840 \pm 537$ \\
$1: 1000$ & $2.14 \mathrm{E}+04$ & $519.3 \pm 35.85$ \\
$1: 10000$ & $2.45 \mathrm{E}+03$ & $56.26 \pm 5.91$ \\
\hline
\end{tabular}




\section{FIGURE LEGENDS}

Figure 1. Representative chromatograms for $(A)$ low quality control pool of marmoset insulin tryptic peptide (MITP) in marmoset serum (626 pmol/L), (B) marmoset insulin IS in macaque serum, and $(C)$ macaque serum. The expected retention time for MITP is $3.27 \mathrm{~min}$.

Figure 2. Calibration plot for marmoset insulin tryptic peptide (MITP) in eight determinations from $3100 \mathrm{pmol} / \mathrm{L}$ to $24.2 \mathrm{pmol} / \mathrm{L}$. A weighted linear model $(1 / \mathrm{x})$ with linear regression was used to calculate the calibration curve. Line equation was $y=1.009 x-6.466, r^{2}=0.9999$.

Figure 3. Marmoset serum response to oral glucose tolerance testing (OGTT; $n=6$ ). A) glucose (open circles), B) insulin (closed squares), and C) glucose and insulin percent change from baseline. Arrow indicates oral administration of dextrose. ${ }^{*}$ indicates $p<0.05$, ${ }^{* *}$ indicates $p<$ 0.01 , a indicates $p=0.0832$, $b$ indicates $p=0.06$.

Figure 4. Comparison of 24 marmoset serum samples that were run by a human insulin radioimmunoassay in 2016 and rerun with the newly developed LC-MS/MS method. The correlation between the methods was high $(r=0.82, p<.0001)$. 


\section{Figure 1}

A

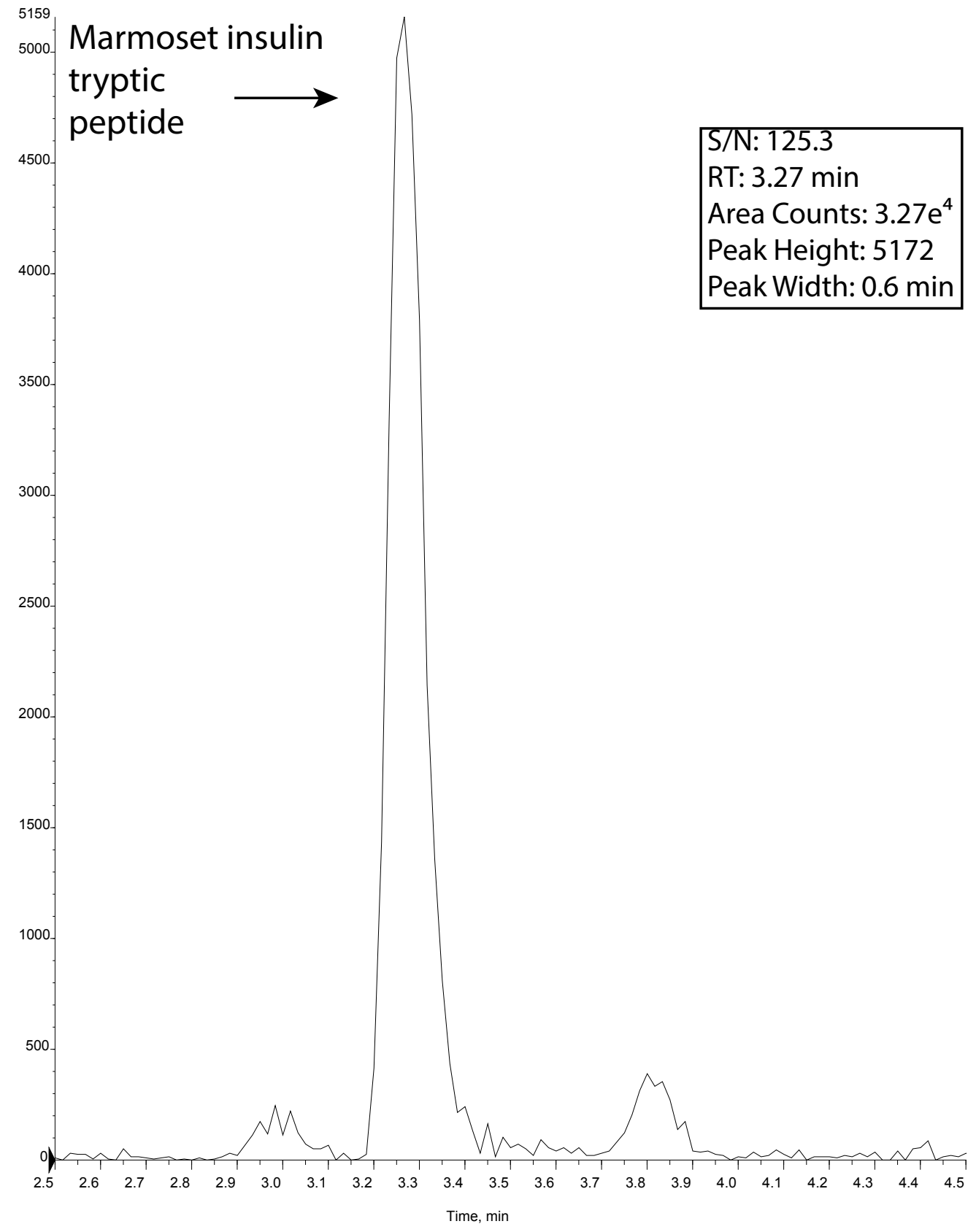

B

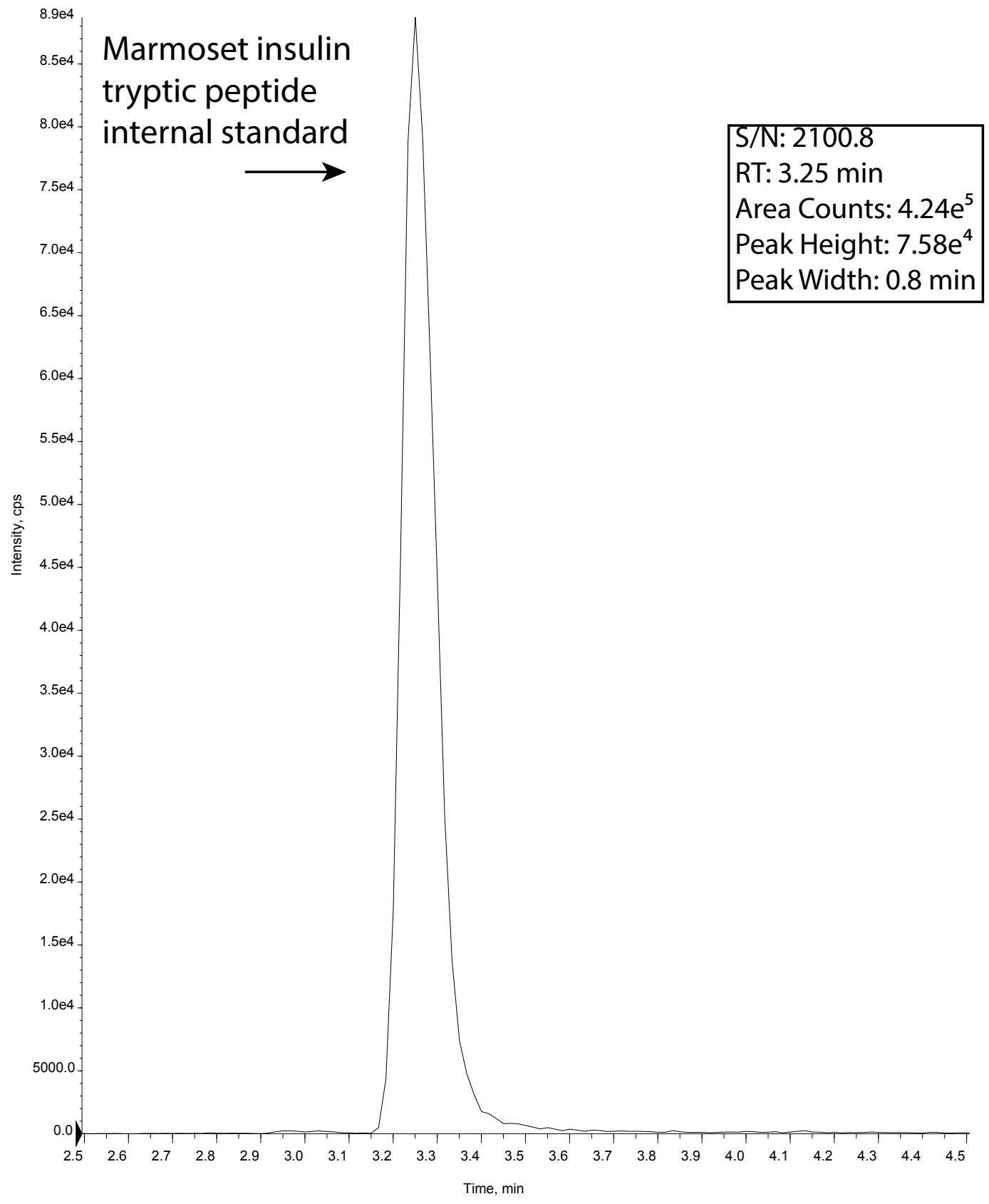

C

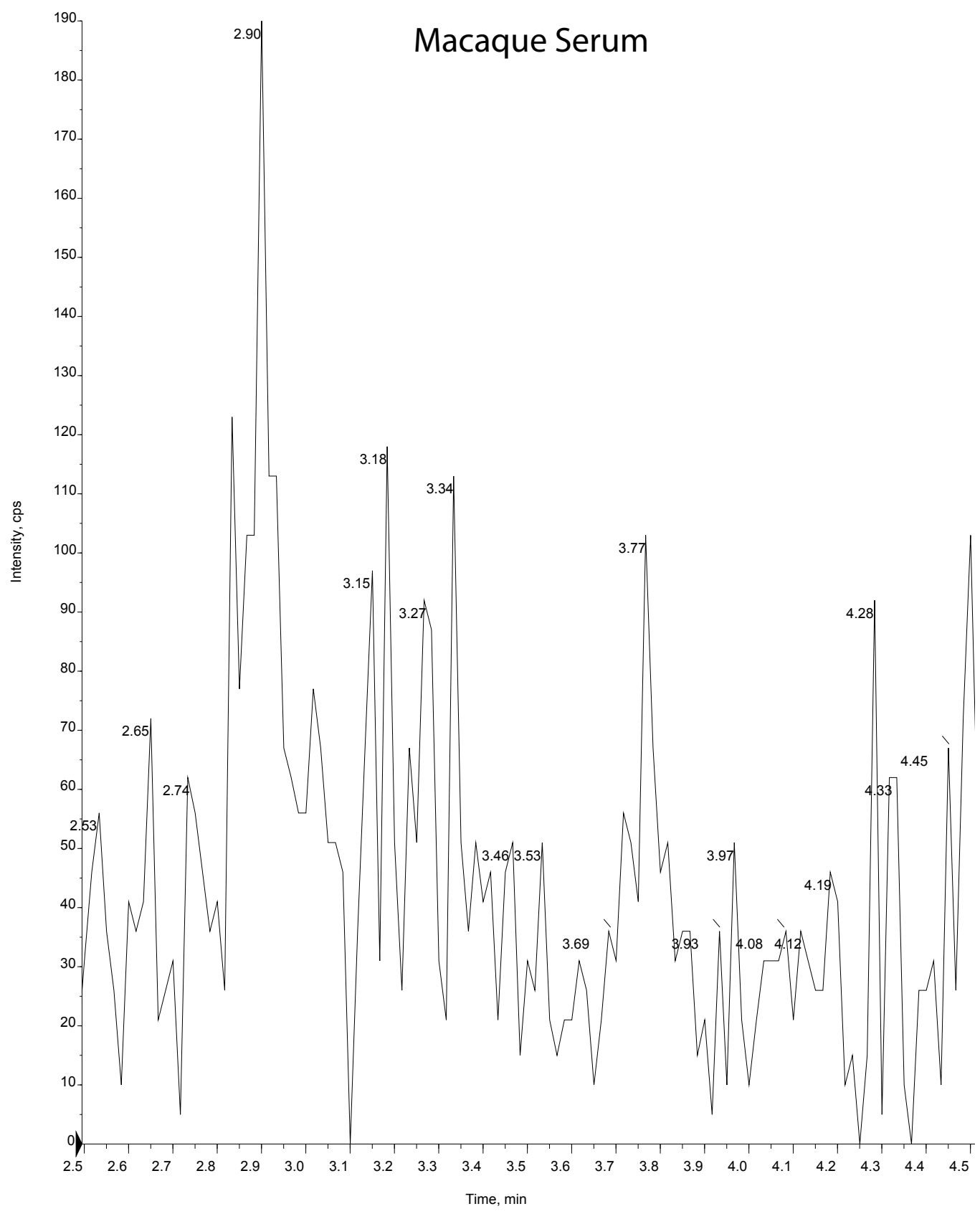


Figure 2

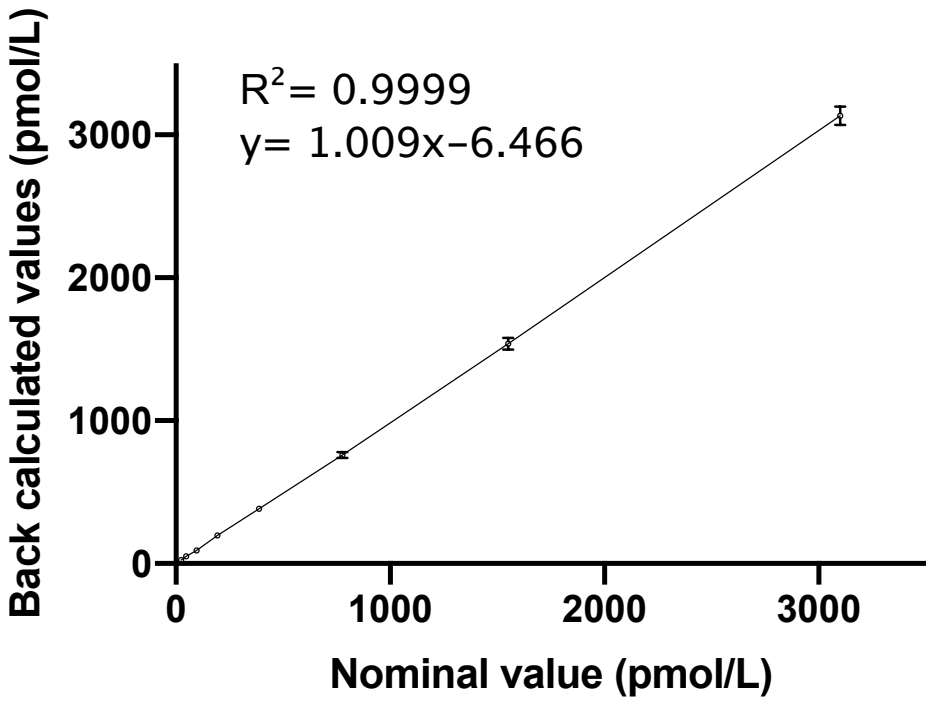


Figure 3
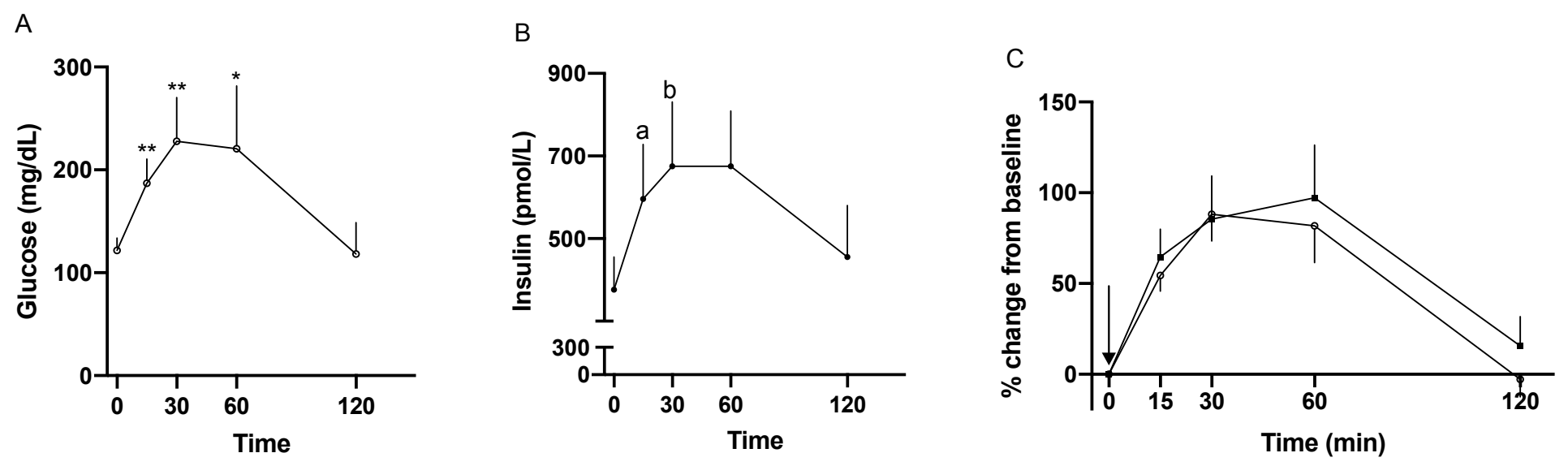
Figure 4

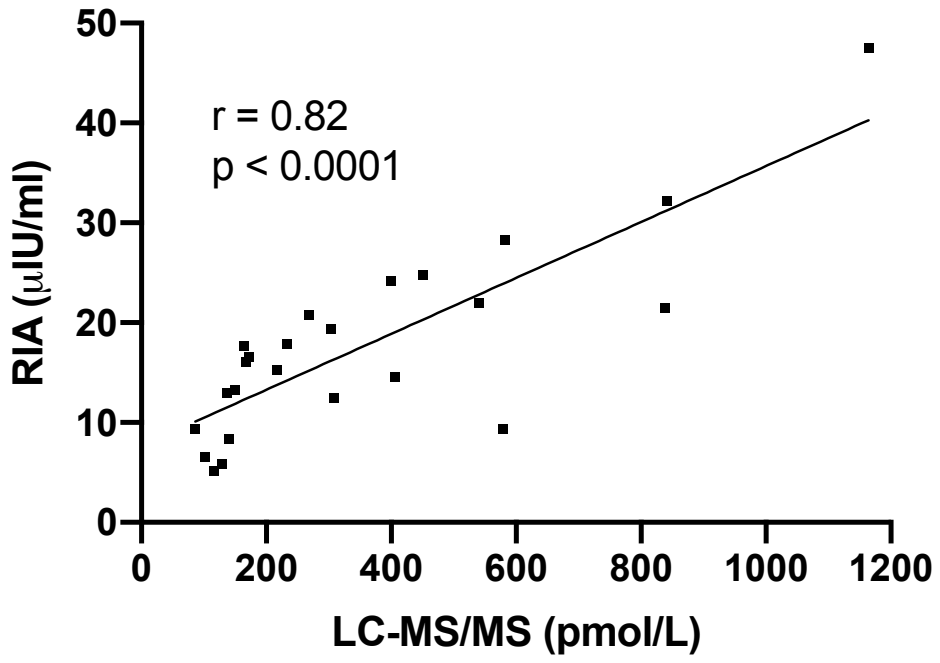




\section{SUPPLEMENTARY INFORMATION}

A

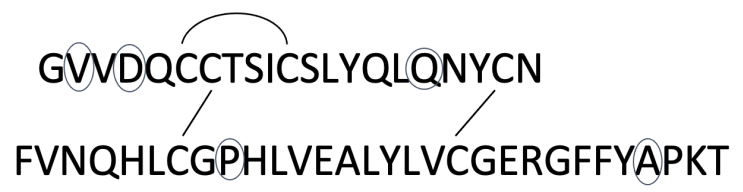
B GFFY
$\mathrm{Y}_{4}$
c $\quad$ GFFY $\stackrel{Y_{5}}{V_{4}}(K)$
$\mathrm{Y}_{4}$

Supplementary Figure 1. (A) Amino acid sequence for intact marmoset insulin. Disulfide bonds are indicated with the lines connecting the cysteine residues. Circles indicate amino acids that differ from human/macaque insulin. (B) Marmoset insulin tryptic peptide (MITP) and (C) marmoset insulin tryptic peptide IS (MITP-IS) sequences and fragment ions monitored by MRM. Heavy labeled lysine $(\mathrm{K})=\left({ }^{13} \mathrm{C},{ }^{15} \mathrm{~N}\right)$.

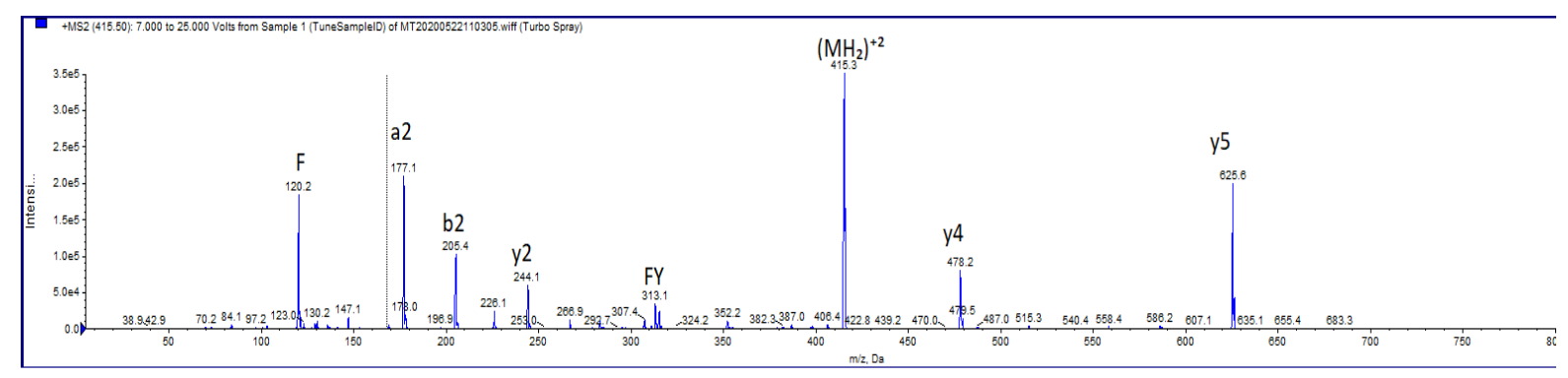

Supplementary Figure 2. MS/MS spectra of marmoset insulin tryptic peptide (GFFYAPK) $\mathrm{MH}_{2}{ }^{+2}$ $(\mathrm{m} / \mathrm{z}=415.3)$. Collision energy ramped from 7 to 25 volts. 